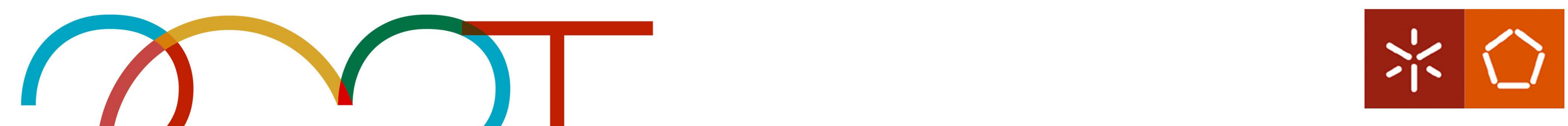

Universidade do Minho

\title{
Biodegradable wet-spun fibers as delivery platforms for the bactericidal effect of the natural-origin \\ biomolecules, cinnamon, clove and \\ cajeput essential oils
}

CENTRO DE CIÊNCIAE TECNOLOGIATEXXTIL

www.2c2t.uminho.pt
Introduction

Essential oils (EOs), which are complex biomolecules composed of volatile compounds, have emerged as a new strategy to deal with bacterial infections and as a valid alternative to synthetic drugs in the treatment of chronic wounds $(\mathrm{CW})$ by promoting the regeneration of damaged tissues.

\section{EOs Drawbacks}

cytotoxic at increased concentrations, which prevents systemic delivery;

present low resistance to degradation by external factors (e.g. temperature, light, moisture);

highly volatile in their free, unloaded form.

\section{Goal of this Research}

Engineer a biodegradable microfibrous target-delivery platform for EOs, that overcomes these biomolecules limitations for applications in infection control.

\section{Materials and Methods}

Wet-Spinning

Non-solvent induced phase inversion approach that allows the production of continuous polymeric microfibers.

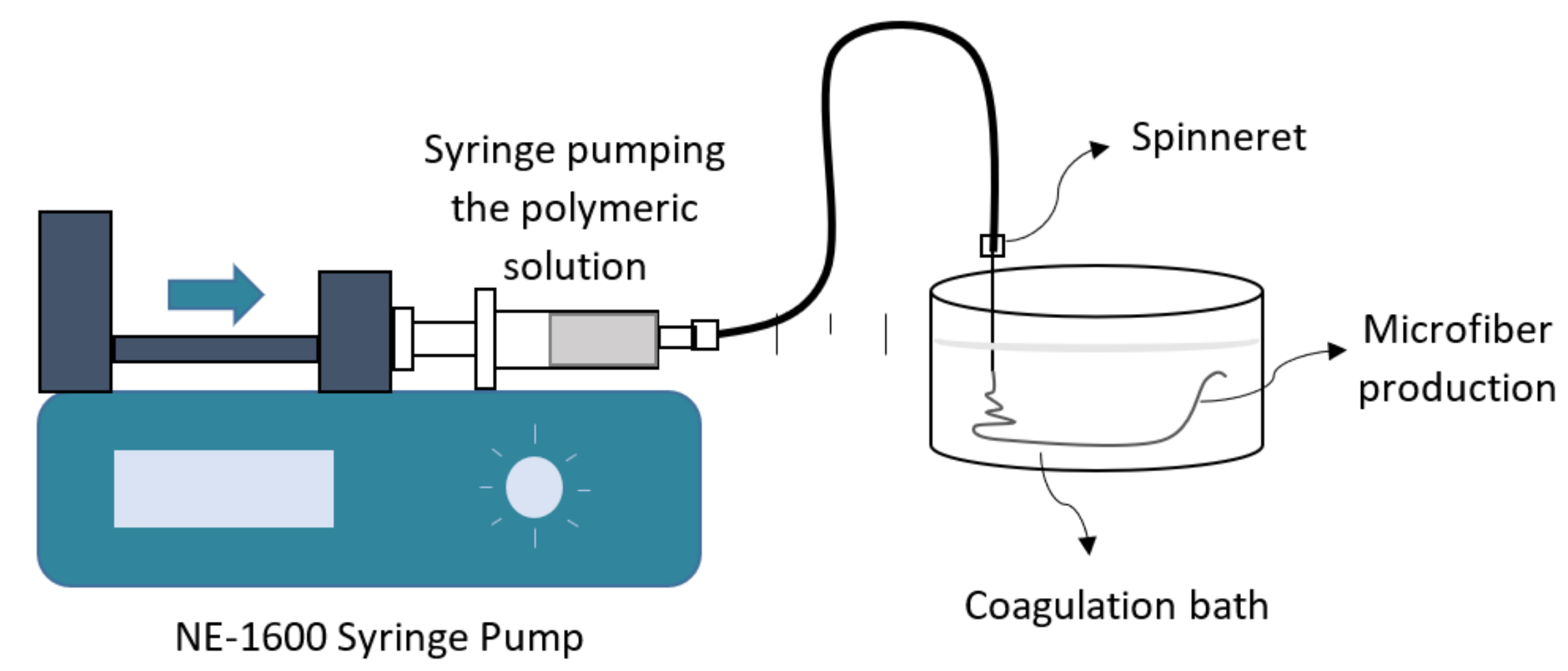

Polymeric solution preparation

Solvents - acetic acid and acetone

Polymer ratio - 3:1 CA/PCL (10/14 wt\%)

Solubilization conditions $-1 \mathrm{~h}$ at $75^{\circ} \mathrm{C}$ and $200 \mathrm{rpm}$

Processing conditions

Flow Rate $-0.5 \mathrm{~mL} / \mathrm{h}$

Needle Gauge - 18

Coagulation bath - Ethanol

EOs Minimum Inhibitory Concentrations (MICs)

\begin{tabular}{lcc}
\hline EOs & $\begin{array}{c}\text { Staphylococcus aureus } \\
\text { MIC }(\mathbf{m g} / \mathbf{m L})\end{array}$ & $\begin{array}{c}\text { Escherichia coli } \\
\text { MIC }(\mathbf{m g} / \mathbf{m L})\end{array}$ \\
\hline Cinnamon Leaf $(\mathrm{CLO})$ & 0.82 & 0.82 \\
\hline Clove $(\mathrm{CO})$ & 0.83 & 0.83 \\
\hline Cajeput $(\mathrm{CJO})$ & 22.38 & 11.19 \\
\hline
\end{tabular}

Fiber Loading: incubation at room temperature at $200 \mathrm{rpm}$ in ethanolbased solution containing the CLO, CO and CJO at $2 \times M I C$ for $72 \mathrm{~h}$ (time determine for maximum loading efficiency).
Results and Discussion

Loading Efficiency

\begin{tabular}{lcc}
\hline EOs & $\begin{array}{c}\text { Loading } \\
(\text { MIC \%, SD }< \pm \mathbf{3 . 0 \%})\end{array}$ & $\begin{array}{c}\text { Concentration } \\
(\mathbf{m g} / \mathbf{m L})\end{array}$ \\
\hline Cinnamon Leaf (CLO) & 14.42 & 0.12 \\
\hline Clove (CO) & 66.08 & 0.55 \\
\hline Cajeput (CJO) & 76.48 & 17.12 \\
\hline Fiber Morphology & F (fiber without agent) & FCLO \\
$\begin{array}{l}\text { No alterations introduced by EOs } \\
\text { loading. }\end{array}$ & \\
$\begin{array}{l}\text { Uniform, homogeneous fibers } \\
\text { (defect free) with an average } \\
\text { diameter of } 5 \text { 54-59 } \mu \mathrm{m} .\end{array}$ & \\
\end{tabular}

Chemical Confirmation of EOs Incorporation

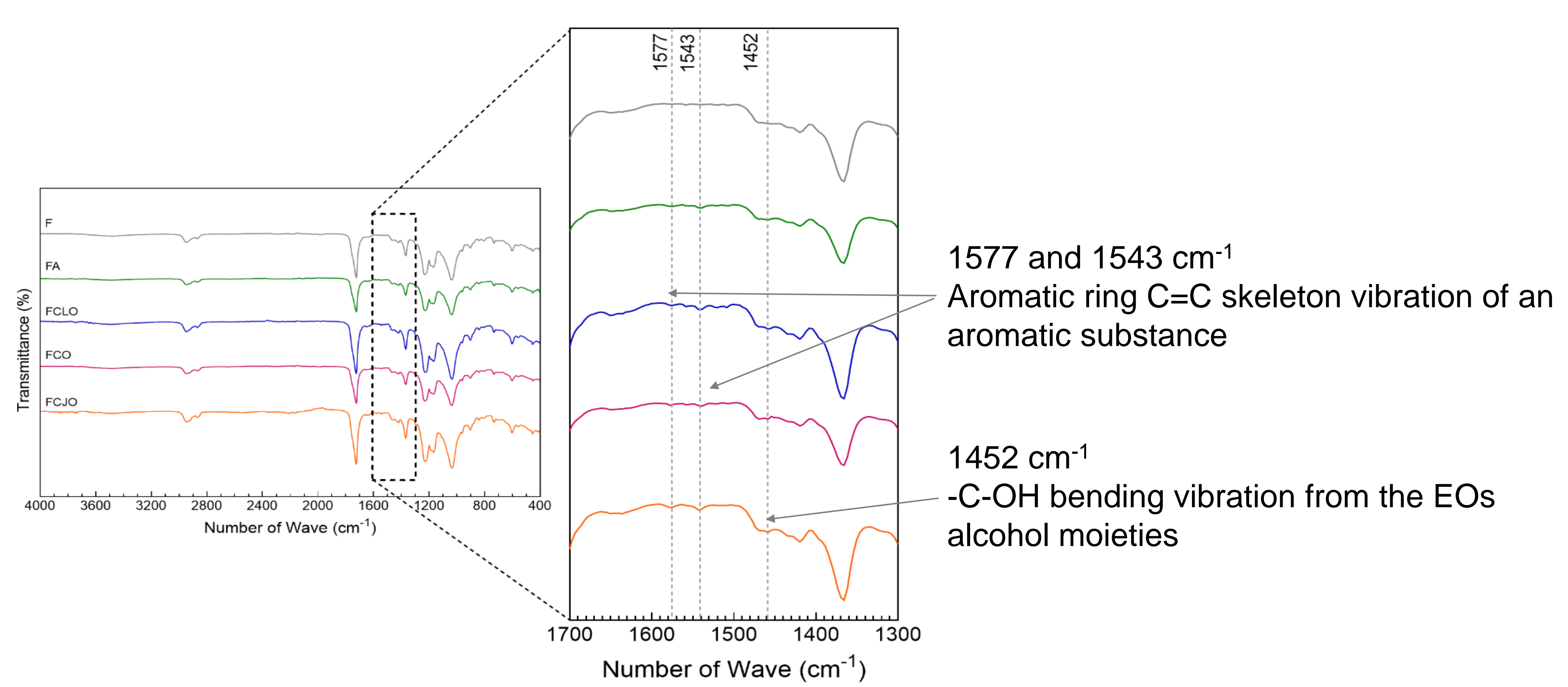

Antimicrobial Action
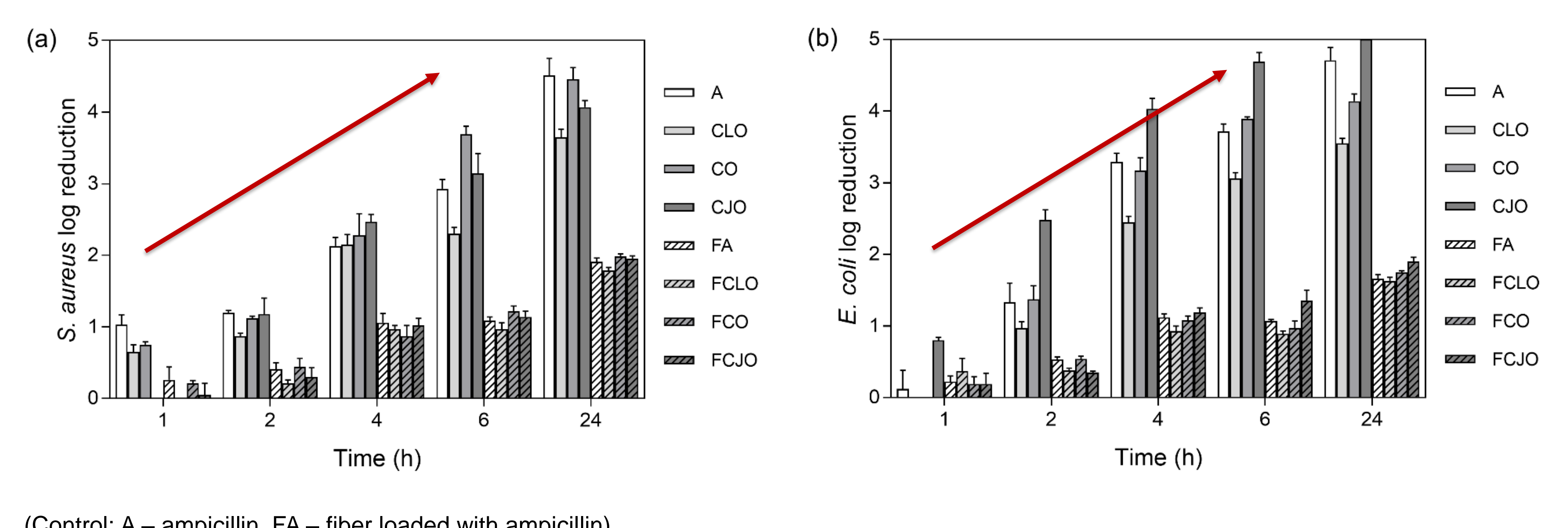

Log reduction was most significant after $24 \mathrm{~h}$ of culture. At this point, it was evident that $S$. aureus was more susceptible to the prolonged action of the EOs than the E. coli, the only exception being the CJO.

Conclusions: The results demonstrated the potential of $\mathrm{CA} / \mathrm{PCL}$ wetspun microfibers loaded with EOs for applications in biomedicine, in which treatment of infections are a main target.

For more details please refer to DOI: $10.3390 /$ biom 10081129 